\title{
Imaginative Instruction: What Master Storytellers Can Teach Instructional Designers
}

Jason K. McDonald

Brigham Young University, jason_mcdonald@byu.edu

Follow this and additional works at: https://scholarsarchive.byu.edu/facpub

Part of the Educational Psychology Commons

\section{Original Publication Citation}

McDonald, J. K. (2009). Imaginative instruction: What master storytellers can teach instructional designers. Educational Media International, 46(2), 111-122.

\section{BYU ScholarsArchive Citation}

McDonald, Jason K., "Imaginative Instruction: What Master Storytellers Can Teach Instructional Designers" (2009). Faculty Publications. 1763.

https://scholarsarchive.byu.edu/facpub/1763

This Peer-Reviewed Article is brought to you for free and open access by BYU ScholarsArchive. It has been accepted for inclusion in Faculty Publications by an authorized administrator of BYU ScholarsArchive. For more information, please contact ellen_amatangelo@byu.edu. 
Running head: IMAGINATIVE INSTRUCTION

Imaginative Instruction: What Master Storytellers Can Teach

Instructional Designers

Jason K. McDonald

Brigham Young University 


\begin{abstract}
Good instructional storytelling engages students' attention and cognitive abilities to the end of more effective learning. Some instructional researchers have also recently discussed whether the principles of storytelling could lead to the same or similar results if applied to educational situations beyond only telling traditional stories. But despite this potential, the principles of storytelling are seemingly underutilized by today's instructional designers. This study investigates what instructional designers might learn from another design field that is more experienced in the art of storytelling, specifically that of film production. Eight filmmakers who have successfully produced films that motivate, inspire, and educate were interviewed to discover what they know about the topic of creating effective instructional stories. The results of these interviews, which will help instructional designers learn and apply storytelling principles, are analyzed to help further illustrate an inventive approach for the creation of instructional environments.
\end{abstract}


Imaginative Instruction: What Master Storytellers Can Teach

Instructional Designers

Stories play a crucial role in human learning. As Schank (2005a) recently concluded Stories have been at the center of human consciousness for a long time. People tell stories, and the stories they tell shape who they are. People hear stories and remember those that resonate deeply with them. . . Good education requires good stories. (p. 5)

Stories can motivate people to make significant and lasting behavioral changes (Denning, 2004; Singhal \& Rogers, 1999), help them meaningfully interpret other experiences (Bruner, 2004/ 1987), and give them context to use learned information in real-world environments (Andersen, 2004; Jonassen \& Hernandez-Serrano, 2002). Postman (1989) argued that peoples' sense of identity is closely associated with the stories they tell. Schank (1990) hypothesized that stories are a fundamental component of human memory, and the foundation of even the most basic mental events. And there has even been some discussion about how the principles of storytelling might lead to these same or similar results if applied to instructional situations beyond only the telling of traditional stories (e.g. Parrish, in press; Schank, 2005a). But despite this considerable potential, the method of story and the broader principles of storytelling are seemingly underutilized by today's instructional designers (Hokanson \& Fraher, 2007). This is true despite recent discussions of both the philosophical foundations of instructional storytelling (e.g. Wong, Pugh, \& The Dewey Ideas Group, 2001), and the practical techniques for using stories that teach (e.g. Mooney \& Holt, 1996; Schank, 2005b).

Other fields, however, are much more experienced in the art of storytelling, and interested instructional designers can borrow principles from these fields to help improve instruction and learning. One such field is film production. Great cinematic stories help people 
learn some of the most difficult-to-understand concepts about the human condition. Expert filmmakers teach by applying well-understood principles of story design to help audiences care about, and think carefully about, the action portrayed on the screen (McKee, 1997). Some theorists also hypothesize that great films are universal, meaning their themes are recognizable and understandable by most cultures (e.g. Vogler, 2007). This, too, can be significant for instructional designers, as developing instruction for different cultures becomes an ever-more important goal (Rogers, Graham, \& Mayes, 2007).

Of course, instructional designers have historically been very interested in researching educational film. However, many studies have applied traditional message design and instructional design principles to film production, rather than considering how principles of good film design can inform instructional design (for a review of how film has traditionally been researched in education, see Wisher \& Curnow, 2003). When instructional researchers have examined how film theory may apply to education (e.g. Boyle, 2002), they typically appeal to historical studies of film as a medium, analyze examples of good film with which they are familiar, or study the effect of films they create for use in educational environments. Yet given the strong storytelling tradition in the film industry it also seems relevant to ask if film producers also know something about stories that could be helpful to instructional designers. The purpose of this study was to investigate storytelling principles great filmmakers use when practicing their craft, and how those principles could be applied to help create better instructional environments.

Method

For this study, eight filmmakers who have successfully produced films that motivate, inspire, and educate were interviewed to discover what they know about the principles of instructional storytelling. Interview subjects were selected based on three criteria. The first 
criterion was expertise. All interview subjects had at least ten years experience in film production, and all have been recognized by their peers as expert storytellers. The second criterion was diversity in filmmaking experience among the group of interviewees as a whole. Selected producers were experienced in different cinematic formats, including feature film, documentary, and industrial/training film. Additionally, some producers had diverse backgrounds beyond production experience, including one who had been department chair of a university-level film studies program and one who founded a well-known film festival. The final criterion was experience with storytelling in educational environments, for example production of films for high schools, university, or corporate training. Although this sampling procedure does not allow conclusions to be generalized to all filmmakers or storytelling situations, this study's purpose was not to discover what the average filmmaker may know, but rather to explore what exemplary filmmakers know about storytelling that can be applied to instructional design.

Each interview was based on a set of common questions, which prompted interviewees to share their unique accounts of how storytelling principles could help improve instruction. Some of these questions included: a) what do you believe are the fundamental characteristics of good stories that contribute to human learning? b) how do you craft the stories you tell?; and c) what advice do you have for educators who are interested in better using stories as a method of instruction? Interviewees were also allowed to respond to the general issue of instructional storytelling with other ideas that may not have been elicited from any specific question.

Each interview was recorded and transcribed. Interview subjects were sent a copy of their interview to allow them to approve or correct the statements they made. Each transcription was then coded and analyzed for patterns and common themes that seemed to best illustrate the issue of storytelling as a method of learning and instruction. These results are presented through rich 
descriptions, based on one or more interviewee responses that exemplify the patterns and themes discovered in the interview data. Individual comments are included at length, with minor editing for clarity, as illustrations of each idea. To help triangulate these results, citations from educational and filmmaking literatures are also included as additional illustrations of the concepts. To preserve interviewee anonymity, identifiable information (such as names of people or films) has been edited out of all interview results.

\section{Results and Discussion}

Three meaningful findings emerged from this study. First, many storytelling processes are similar to common instructional design processes, meaning designers may be able to adapt storytelling processes to instructional design more easily than they might think. Second, some of the important principles filmmakers use to engage audiences may help instructional designers create more effective instructional stories. Third, it may also be possible for instructional designers to apply the principles of storytelling in different configurations than those used to craft films or tell stories, and so create new and innovative instructional situations. Each section below describes these findings in more detail.

\section{Similarities Between Storytelling and Instructional Design}

The first finding was that many storytelling processes are similar to common instructional design processes. Three examples are illustrative. First, many interviewed producers discussed the importance of conducting an audience analysis before beginning the story design process. One elaborated, “you've got to know your audience! I feel like we make a big mistake if we don't know our audience. If you don't know who you're trying to reach, you're wasting your time." Second, many producers also discussed the importance of having goals or objectives to guide individual design decisions. As one put it, "if you make a documentary to teach people 
about the suffering of people in Africa so they'll appreciate the situation and donate money, you'll tell the story with that slant. That's your objective." And third, while mentioned much less frequently, other producers discussed the critical role of evaluation in the filmmaking process, including, "small group tryouts, large group tryouts, [and iterative] prototypes to try out the story. You say, 'if it works with this group, and this group, and this group, then we can release it." The producer making this comment then reflected for a moment, and concluded, "it isn't that different in distance learning."

As implied by this comment, these similarities indicate that instructional designers may use what they already know about design to adapt more unfamiliar storytelling principles to instructional purposes more easily than they might imagine. As one interviewee put it

I think a lot of storytelling principles are intuitively understood by most people. . . Good [teachers] are good storytellers. It doesn't mean they're funny. But they're engaging and passionate, and that passion shows in the depth of the stories they tell.

Additionally, finding relationships between different design fields is by no means unique to instructional design and filmmaking. There seems to be current interest in comparing instructional design to other design fields, such as architecture or graphic design. And some recent studies on this topic have also concluded that instructional design could be improved if designers integrated principles and techniques from similar fields into their work (e.g. Kays, 2003; Stubbs \& Gibbons, 2008). As one of the subjects interviewed for this study stated, "storytelling is the creation of meaning out of a series of raw elements." The same could be said of instructional design. Many design fields, including instructional design, have at their core the purpose of making the world more understandable, and this shared purpose should allow 
practitioners in different disciplines to learn from one another in pursuit of the most effective and flexible ways of achieving that goal.

\section{Storytelling Principles}

The second finding was that some of the important principles filmmakers use to engage audiences may help instructional designers create more effective instructional stories. Three of these principles are worth exploring in detail, because they are so central to the craft of filmmaking, because they may be unfamiliar to many instructional designers, and because the interviewed producers described them clearly enough to help designers use them during the instructional design process. These three principles are conflict, authenticity, and entertainment. Each is described in the paragraphs below. However, it is important first to mention that no comment that follows is meant to prescribe a certain storytelling formula. While filmmakers have translated storytelling principles into practical techniques (some of which are included below as illustrations of each principle), when considering how to them their own work instructional designers are encouraged to focus on the needs of local situations, rather than force their use of instructional storytelling into rule-based prescriptions.

Conflict. The first principle is conflict, or the dissonance created when a character's goals and desires clash with the goals of another character, with environmental forces, or even with another desire the same character simultaneously holds. Conflict motivates the action in all good stories. It is so important to storytelling, in fact, that one well-known story consultant has called conflict "the soul of a story" (McKee, 1997, p. 211). To create conflict, storytellers often use a dramatic structure as a template for their story's action. A common problem of amateur storytellers is they only relate a series of events in sequence and believe those events alone 
define a story. Using a dramatic structure allows storytellers to plot events into patterns of conflict, helping them ensure the action builds and resolves to the ends they aim to achieve.

One of the most common dramatic forms is the three-act structure, which breaks a story's events into three periods of rising action, framed by major decisions or turning points that set up a conflict, create risk for major characters, and resolve to a conclusion directly based on characters' responses to the conflict (Trottier, 2005). One interview subject described how he uses this structure:

I'll take any story idea, and without even thinking about it my mind starts to break it down into three acts. Where is the beginning, where is the middle, where is that turning point? What is the climax? What is the dénouement? I just automatically put the story into that structure. Other filmmakers will say I'm putting chains around myself. But for me those are the rules of the medium in which I'm creating. But I create the structure so then I can depart from it. I have the rules and the structure so then I'm free to create something new.

In other words, the three-act structure is this producer's scaffolding, supporting the emerging story form until it is well-enough developed that he can modify it to better meet the circumstances in which the story will be used.

But instructional designers do not have to be experts in this or any more complicated dramatic structure if they want to create conflict in an instructional story. Another producer simplified the principle of conflict into a two-step structure:

Good stories present choices. Good stories illustrate the outcome of those choices. Good stories have no scenes or elements that don't ultimately lead to a choice that a character needs to make. Stories should illustrate the consequences of choices, not as a dead-end, 
but that those consequences themselves lead to more choices. A good story, from beginning to end, is a train of choice-consequence-choice-consequence-choiceconsequence. Bad stories, by contrast, have lots of scenes with no choices or consequences. The scenes are just there, and you yawn through them. If you look at the whole movie you don't know why it was bad; you say "it just dragged." But if you go back and analyze the development of that story you could see there were parts of the story where no choice was presented and there were no consequences. (see also McKee, 1997)

It follows, then, that designers can improve instructional stories by analyzing the content and determining whether the major elements are either a choice or a consequence of a choice. If not, designers may improve the story's effectiveness by restructuring the story to better emphasize the choice-consequence pattern, or the patterns found in any other dramatic structure they may be working with.

Authenticity. The second principle is authenticity, or the sense of credibility created when characters display genuine emotion and react in believable ways. Authenticity helps viewers feel empathy for characters, and recognize themselves (their emotions and their reactions) in those characters. And when viewers can identify with a character they often imagine how they would react to the circumstances they see that character face. As one interviewed producer put it [Members of the audience are] exploring, subconsciously or consciously, what they would do if they were in that situation on the screen. And rather than simply reading off a page, "here is what you ought to do in this situation," audience members, like learners in a classroom, are exploring options of behavior. They're making decisions and choices vicariously, and extremely vividly, to the point that they're forgetting they're sitting in a 
dark room with 350 strangers, and they're completely in the world of this theme. And they're willing to put their prejudices aside, and sometimes are even willing to put their morality aside, and explore that theme fully with the characters in that story. . . By extension they [vicariously] made those choices by becoming [emotionally] involved in the film. Those choices become part of them. And they walk away changed people. In response to an authentic story, a viewer is often willing to change a long-held belief or behavior, or accept some type of personal transformation or self-improvement (Seger, 2003).

To create authenticity, storytellers often base their characters' emotions and reactions on real people and real situations. One interview subject described how he created a sense of authenticity for a documentary on families:

I put out a casting call that we were looking for families who have had some specific experience where they came to a moment in their lives where they were too busy and realized they didn't have enough family time. That family can speak from a point of authenticity about what they had to do to correct the problem. If I cast any old family and had them talk about family time it would come across as platitudes. ... It's really is a matter of finding people with the life experience to speak from authenticity. I think people can see when other people aren't authentic.

Schank (2005b), in his discussion of authentic storytelling in education, agreed: "have real people tell real stories in real language. If the real people aren't good storytellers, coach them so that they can become good storytellers. We know when we are hearing a real story" (p. 132). But even fictional stories can still be authentic. As one producer stated

Even in fantasy stories the basic human elements are there. We all need to be loved. We all need to be cared for. We want to be listened to. We want to feel we're making a 
contribution. I think there are some common themes in every fantasy, even with completely fictional characters, that are based on someone or some situation that someone's actually lived.

Or, as another producer put it, storytellers should avoid, "straw characters without any real psychological or emotional depth to them."

Entertainment. The third principle is entertainment, or the ability a great story has to capture the attention and interest of viewers. The sometimes-stereotypical distinction between entertainment and education was not made by those interviewed for this study. They saw education and entertainment as two manifestations of the same phenomenon. Said one, "I don't believe you can instruct unless you also entertain. I also believe that it's not worth entertaining unless you also instruct. The two are related. ...The best form of entertainment is when you're also instructing."

There is no simple formula for creating an entertaining story. Some interview subjects use humor to make a story more entertaining, "humor can really make you stop and think." Others encouraged the use of mystery and anticipation:

Can you imagine constructing a learning experience utilizing Hitchcock's strategies for revealing information, which he did only a little bit at a time and at very selective places in the film, to create a certain effect in the audience? For Hitchcock that effect was always suspense, to keep the audience on the end of their chairs. To do that you have to give out information in very selective and very carefully pre-determined ways. I suspect that's a very difficult thing to do, to use a strategy like that where you will actually set up a class so students discover pieces of information at strategic points where those pieces of information will have maximum impact and meaning. But I also suspect that would be a 
very interesting exercise in a school of education. I think Hitchcock would probably have a lot to teach teachers about the revelation of information.

Perhaps the most interesting strategy for creating an entertaining story was to leave some of a story's details unstated or unseen, to encourage viewers to think more deeply about the action and its implications. As one interviewed producer described

I do feel it weakens the power of the story and possibly of the teaching as soon as a viewer realizes that the reason they're watching something is to learn. They may get the points, but do the points get into their hearts or even deep enough in their minds? ... We need to put our hammers away and just let some of these stories be told. Just tell the story! And in the film don't try to say to the viewer, "are you sure you got this point?" . . . I think part of human nature is that we want to discover things for ourselves. It's a much more rewarding experience as a film viewer if I put something together that I think nobody else got. If people feel like they're being preached to I think it's a part of human nature for them to stop paying attention. There's a huge segment of society that doesn't want to be preached to! But if the message of a story comes either subconsciously, or in a way that the audience feels they're getting it or finding it themselves, that's a whole different thing. They don't believe they're being spoon-fed, but they're finding it.

In other words, making an instructional story overly explicit may actually decrease its effectiveness, because those stories are less compelling and less entertaining, and people are unlikely to learn when they simply stop paying attention. As one producer concluded, "a story that doesn't have a compelling narrative ... is as engaging as just looking at a pile of papers. ... Yes, all the information is there, but you just do not want to try to access it." 


\section{Operational Principles and Storytelling}

The third finding was that it may be possible for instructional designers to apply the principles of storytelling in different configurations than those used to craft films or tell stories, and so create new and innovative instructional situations. This finding emerged as interview subjects described how they have seen storytelling principles used in learning situations that may not commonly be recognized as a conventional story. When designers in any field apply abstract principles to novel situations, they often create new design patterns that reify the underlying structures controlled by those principles. So even though a new design may have very different surface characteristics from other applications of the same principle, it may also encourage the same or similar results because it is the abstract principle that expresses the essence of an approach, not the surface characteristics (Rogers, Hsueh, \& Gibbons, 2005). These abstract principles are known as operational principles, or the most basic and conceptual definition of a design pattern expressed only in terms of the characteristics required for the design to function (Polanyi, 1962).

Operational principles can sometimes be conceptually difficult to understand. Consequently, many designers only imitate the normal configurations of those principles when creating new designs, or "the overall shape and arrangement commonly agreed, for whatever reasons, to best realize the operational principle" (Vincenti, 1991, p. 762). Vincenti illustrated with the example of an airplane. Although an airplane's operational principles are expressions of the physics of flight, the normal configuration of an airplane directs more tangible matters like the shape and composition of wings, engines, and other characteristics that result in a form of craft with which most readers would be familiar. Nothing about the operational principle 
mandates this form, but historical precedent, experience in aircraft design, and economic considerations make the configuration likely.

But the value of operational principles is precisely their abstractness, particularly when designers encounter new situations for which the normal configuration is inadequate. As Rogers, Hsueh, and Gibbons (2005) explained

From the operational principle, designers can generate many configurations, of which the "normal" configuration is just one of many options. ... Although each configuration might have varying degrees of practicality, by going back to the operational principle involved, the designer gains the freedom to question the assumptions of the standard design, allowing for more possible outcomes. (p.1)

In the case of instructional storytelling, if designers understood storytelling principles as operational principles, they may be able to create new instructional patterns for situations where a traditional story might be insufficient or otherwise limiting. As one interview subject stated, 'even if they're not 'telling a story,' if teachers use those principles [in new ways] . . . their instruction becomes a story." For example, some instructional approaches already exemplify the principle of authenticity, such as problem-based learning (e.g. Barrows, 1996), model-centered instruction (e.g. Gibbons, 2001), and cognitive apprenticeship (e.g. Collins, Brown, \& Newman, 1989). Designers using these and similar approaches might be able to augment and strengthen the authentic learning experience by incorporating what storytellers also know about authenticity. One illustration might be the storytelling technique described earlier of basing even fictional examples on real people and events. This corresponds to the use of authentic examples in problem-based learning, where Barrows insisted that medical students study real patient cases 
rather than fabricated examples, to help ensure students learn the most applicable topics necessary for medical practice.

With a little creativity, then, instructional designers may be able to create new configurations of other storytelling principles, and so be better able to reach the goals they intend to achieve. Could instructional designers find ways of building conflict into the expression of instructional content? The principle of conflict sound similar to a strategy described by Bransford, Brown, and Cocking (2000), of presenting students with contradicting information that compels them to confront misconceptions they hold about a subject, to help them develop more accurate conceptual models. Or, could designers craft more engaging instructional experiences by applying some of what storytellers know about entertainment, such as allowing students to discover on their own information to be learned? Barrows (1996), for example, believed that problem-based learning encourages students to become more engaged in their own education precisely because the approach requires them to search and explore topics rather than having information explicitly presented through lectures or similar activities. By considering how the underlying operational principles of storytelling might apply to the design problems they face, instructional designers may discover that configurations like these become more obvious solutions.

\section{Conclusion}

This study recommends that instructional designers learn and apply the principles of storytelling in their own work, as illustrated through the data gathered from these interviewed film producers. Designers who use rich instructional stories, or who more broadly apply the principles of storytelling in other instructional situations, are likely to engage students' attention and cognitive abilities to the end of more effective learning. Storytelling is a potent instructional 
approach that draws on principles which may be foreign to some instructional designers. Yet because of their similarity to other, more common instructional design processes, designers can confidently adopt many storytelling principles to the improvement of the learning environments they develop. As McDonald and Gibbons (in press) concluded, instructional designers should "be willing to look for [instructional] solutions in a wide variety of settings beyond only those that are fashionable, familiar, or comfortable," so they can accomplish a wider range of goals than might otherwise be possible. The principles of storytelling are a valuable addition to the body of instructional design practice, to help designers who are interested in using an inventive approach in the creation of instructional environments. 


\section{References}

Andersen, C. (2004). Learning in "As-if" Worlds: Cognition and drama in education. Theory into Practice, 43(4), 281-286.

Barrows, H. S. (1996). Problem-based learning in medicine and beyond: A brief overview. In L. Wilkerson \& W. H. Gijselaers (Eds.), Bringing problem-based learning to higher education: Theory and practice (Vol. 68, pp. 3-12). San Francisco: Jossey-Bass Publishers.

Boyle, T. (2002). Towards a theoretical base for educational multimedia design [Electronic Version]. Journal of Interactive Media in Education. Retrieved December 27, 2007 from http://www-jime.open.ac.uk/2002/2/boyle-02-2.pdf.

Bransford, J. D., Brown, A. L., \& Cocking, R. R. (2000). How people learn: Brain, mind, experience, and school (Expanded ed.). Washington, DC: National Academy Press.

Bruner, J. S. (2004). Life as narrative. Social Research: An International Quarterly of Social Sciences, 71(3), 691-710. (Reprinted from Social Research, (54)1, Spring 1987)

Collins, A., Brown, J. S., \& Newman, S. E. (1989). Cognitive apprenticeship: Teaching the crafts of reading, writing, and mathematics. In L. B. Resnick (Ed.), Knowing, learning, and instruction: Essays in honor of Robert Glaser (pp. 453-494). Hillsdale, NJ: Lawrence Erlbaum Associates.

Denning, S. (2004). Telling tales. Harvard Business Review, 82(5), 102-111.

Gibbons, A. S. (2001). Model-centered instruction. Journal of Structural Learning and Intelligent Systems, 14, 511-540.

Hokanson, B., \& Fraher, R. (2007). Narrative structure, myth, and cognition for instructional design. Educational Technology, 48(1), 27-31. 
Jonassen, D. H., \& Hernandez-Serrano, J. (2002). Case-based reasoning and instructional design: Using stories to support problem solving. Educational Technology Research and Development, 50(2), 65-77.

Kays, E. J. (2003). Architecture and instructional design: A conceptual model for e-learning. Unpublished Dissertation (PhD), Capella University, School of Education.

McDonald, J. K., \& Gibbons, A. S. (in press). Technology I, II, and III: Criteria for understanding and improving the practice of instructional technology. Educational Technology Research and Development.

McKee, R. (1997). Story: Substance, structure, style, and the principles of screenwriting. New York: Harper Collins Publishers, Inc.

Mooney, B., \& Holt, D. (Eds.). (1996). The storyteller's guide: Storytellers share advice for the classroom, boardroom, showroom, podium, pulpit, and center stage. Little Rock, AR: August House, Inc.

Parrish, P. (in press). Aesthetic principles for instructional design. Educational Technology Research and Development.

Polanyi, M. (1962). Personal knowledge: Towards a post-critical philosophy (Corrected ed.). Chicago: University of Chicago Press.

Postman, N. (1989). Learning by story. The Atlantic, 264(6), 119-124.

Rogers, P. C., Graham, C. R., \& Mayes, C. T. (2007). Cultural competence and instructional design: Exploration research into the delivery of online instruction cross-culturally. Educational Technology Research and Development, 55(2), 197-217. 
Rogers, P. C., Hsueh, S.-L., \& Gibbons, A. S. (2005, July). The generative aspect of design theory. Paper presented at the Fifth IEEE International Conference on Advanced Learning Technologies (ICALT'05), Kaohsiung, Taiwan.

Schank, R. C. (1990). Tell me a story: Narrative and intelligence. Evanston, IL: Northwestern University Press.

Schank, R. C. (2005a). Every curriculum tells a story. Retrieved November 1, 2008, from http://www.socraticarts.com/about/SCCwhitepaper.pdf

Schank, R. C. (2005b). Lessons in learning, e-learning, and training: Perspectives and guidance for the enlightened trainer. San Francisco, CA: Pfeiffer.

Seger, L. (2003). Advanced screenwriting: Raising your script to the Academy Award level. Los Angeles, CA: Silman-James Press.

Singhal, A., \& Rogers, E. M. (1999). Entertainment education: A communication strategy for social change. Mahwah, NJ: Lawrence Erlbaum Associates.

Stubbs, S. T., \& Gibbons, A. S. (2008). The power of design drawing in other design fields. In L. Botturi \& S. T. Stubbs (Eds.), Handbook of visual languages for instructional design: Theories and practice (pp. 33-51). Hershey, PA: IDEA Group, Inc.

Trottier, D. (2005). The screenwriter's bible: A complete guide to writing, formatting, and selling your script (4th ed.). Beverley Hills, CA: Silman-James Press.

Vincenti, W. G. (1991). The scope for social impact in engineering outcomes: A diagrammatic aid to analysis. Social Studies of Science, 21(4), 761-767.

Vogler, C. (2007). The writer's journey: Mythic structures for writers (3rd ed.). Studio City, CA: Michael Wiese Productions. 
Wisher, R. A., \& Curnow, C. K. (2003). Video-based instruction in distance learning: From motion pictures to the Internet. In M. G. Moore \& W. G. Anderson (Eds.), Handbook of distance education (2nd ed., pp. 315-330). New York: Routledge.

Wong, D., Pugh, K., \& The Dewey Ideas Group. (2001). Learning science: A Deweyan perspective. Journal of Research in Science Teaching, 38(3), 317-336. 